\title{
CARE MANAGEMENT OF THE PATIENT WITH AMPUTATION IN THE INFERIOR LIMB
}

\author{
Mariana ANGHELE RN, PhD $^{1 *}$, Valeriu ARDELEANU MD, PhD $^{1}$, Ștefan Claudiu \\ CHICOŞ MD, PhD1 \\ ${ }^{1}$ Dunărea de Jos University, Domnească str. no.47, Galați, postal code 800008, Romania, \\ mariana.anghele@ugal.ro, \\ ${ }^{2}$ City Hospital Târgu Bujor, G-ral. Eremia Grigorescu, str. no. 97, Tg.Bujor, postal 805200,
}

\begin{abstract}
Summary: Lower limb amputation is a therapeutic solution for peripheral vascular disease that affects more and more people on long term, both socially and emotionally.

Changing the appearance and shape of the body requires changes in the patient's life and his environment. Most patients are afraid of these changes, the help of professionals and family being essential for solving medical and social issues. According to the recommendations of the World Health Organization, patients' evaluation should be extended from deficiencies caused by segmentation to structural deficiencies, through all functional, educational and professional aspects of human life.

The purpose of the article is to present the complex way of care and rehabilitation of the patient with amputation at the level of the inferior limb, starting from qualified medical care to social and occupational care.

Successful rehabilitation of patients with amputation in the inferior limb is a major objective of the multidisciplinary team.
\end{abstract}

Keywords: amputation, blunt care, rehabilitation.

\section{Introduction}

Amputation is the traumatic or surgical removale of a limb or segment thereof. The causes of amputation are vascular complications of diabetes mellitus and arteriosclerosis - when other revascularization procedures have failed (Swaminathan et al, 2014), traumas, tumors, infestation necrosis (Bjerke and Stuhlmiller, 2015), rarely congenital deficiencies where harmonizing the somatic and psychological development of the individual is desired. Often, both the patient and the surgeon wish the salvage of the affected limb - but chronic pain, infectious complications and functional impotence ultimately result in amputation (Ertl et al, 2016).

There are more than 2 million people in the US who have suffered limb amputation, estimated to arrive 3.6 million in 2050 (Ziegler-Graham et al, 2008), and in Australia more than 8000 amputations per year have been performed (Dillon et al, 2017). In Romania, according to a five-year study published in 2015, 24.312 non-traumatic amputations were practiced, of which 16.873 in diabetic patients (Vereşiu et al, 2015).

Method - preparation of patient care and rehabilitation plan

Inferior limb amputations raise severe physical, psycho-emotional and social issues on long term. Thus, loss of a inferior limb limits patient mobility, affecting daily activities and generating a negative impact on his role in society. Often the partial amputation of the inferior limb, regardless of the level at which it is practiced, may cause local failure and complications, and secondary amputation is subsequently required. Evolution may vary depending on the patient's health and co-morbidity: surgical wound infections, phantom gait limb, post amputation, death.

In most cases, the healthcare provided to these patients is reduced to surgical treatment and technical assistance (Tăbîrţa, 2016). Surgery aims to maintain or improve the quality of life of the patient, improving symptomatology and improving function. The care of amputated patients should be provided by a multidisciplinary team, starting with the period of hospitalization for surgery and ending with community and professional integration, going through several stages (Esquenazi, 2004; Esquenazi and Meier, 1996):

The preoperative stage is the stage where the patient is consulted by the physician with the multidisciplinary team and the amputation is discussed only if there is no alternative. The level of amputation and residual length of the limb is determined and the patient's rehabilitation plan is then conceived. The consent of the patient or legal representatives is essential for practicing 


\section{THE ANNALS OF "DUNAREA DE JOS" UNIVERSITY OF GALATI}

FASCICLE XV ISSN - 1454 - 9832 - Vol. 2/2019

surgery. Risks, benefits and alternatives will be presented to the patient and his family.

The preoperative training requires physical examination, vital function measurement, nutritional level evaluation, laboratory analysis (including for MRSA port) electrocardiogram, pulmonary radioscopy, Doppler echography, angiography, oscillometry. The comorbidities will be evaluated and the patient balanced appropriately. The physical strength, coordination capacity and keeping balance will be appreciated to assess the patient's recovery potential. The risk of falling is taken into account as it increases significantly after amputation, often requiring surgical re-intervention (Gooday and Hunter, 2004).

The physical preparation for the intervention will be done by recommending a proper diet, performing personal hygiene and skin preparation, administering preanesthetic medication and performing drug sensitivity tests.

The surgical amputation is performed under anesthesia, the type being determined by the anesthetist after the patient's examination and the risk score. The incision site, surgical technique, the size of the remaining limb respects the healthy tissue to guarantee healing per primam. Also, the surgeon shapes the surgical blunt to allow subsequent prosthesis. The blunt will be sterile, with an elastic stocking that will support both the dressing and the possible drainage tubes.

The postoperative stage requires medical care such as respiratory airways assessment and maintenance, respiratory and circulatory support, hyperbaric oxygen therapy, monitoring of vital parameters, patient mobilization to prevent thromboembolism, surveillance of dressing and drainage tubes, signs and symptoms that may indicate the occurrence of possible complications in patient evolution.

An important role is the management of pain. Bone and tissue lesions cause nociceptive pain and direct neural trauma and central sensitization involve neuropathic pain (Neil, 2016). This complicated type of pain can persist over a period of several years. Ineffective analgesia may have an impact on the patient's psyche, the recovery and the installation of chronic pain (Wartan et al, 1997).

Immediately after surgery the pain is acute, persistent, limited to the surgical wound, requiring the administration of opioid analgesics. The acute pain disappears in the first few weeks of intervention, but its persistence may indicate the occurrence of infection, neuroma and heterotopic ossification after traumatic amputations (Potter et al, 2010).

Phantom pain occurs in most cases in the first week of amputation and will disappear in the first year. In the presence of certain risk factors (advanced age, repeated interventions, chronic pain, bilateral amputations), some patients will retain this type of pain throughout their lives (Wartan et al, 1997).

Another type of pain is that of the anterior or anterior lumbar spine, sometimes occurring as a result of long bed rest, but also changes in body shape and weight.
The protective absorbent wound dressing will be permanently evaluated for integrity and drainage.

Caring the amputation blunt involves mobilizing it in the first 24-48 hours (Coletta, 2000), modeling it, cleaning the wound, locating the first signs of local infection, fighting edema. The color of the skin, the local temperature, the pulse accessible to the neighborhood artery are evaluated.

The patient will slowly mobilize to prevent muscle spasms, reposition them within two hours to avoid decubitus lesions. It is recommended to perform muscular tension exercises, support on the pillow, to prepare the prosthesis and reduce the incidence of phantom pain (Smeltzer et al, 2008).

A few days after the intervention, the kinesiotherapy begins under the supervision of a specialist, the patient performing isometric exercises to prevent myotrophy, strengthen the resistance of the muscle groups, and maintain joint mobility. It also performs exercises to strengthen and increase the resistance of the intact limb, upper limbs and trunk.

The exercises will be performed at least twice a day, then their complexity and duration will increase according to patient tolerance. The patient will be encouraged to touch and massage the amputation blust, allowing the body to adapt to the new body image but also to reduce phantom pain.

The psychological and emotional support of the patient is permanently ensured by the multidisciplinary team, but also by their dependents, because they can become accustomed to changing their physical appearance and to accept changes in their lifestyle (Pullen, 2010).

Pre-Prosthetic Stage - Prepares the patient for adaptation of the prosthetic device after the healing of the wound. It takes place at the patient's home or in the recovery centers, aiming at the preparation of the blunt for accepting the prosthesis (Kovac et al, 2015). The patient acquires relative independence, moving with the crutches, the metal frame or the wheelchair. It is taught by the nurse how to make the restroom of the resting area with warm water, erase it with gentle, circular movements to stimulate circulation, apply moisturizing cream and bandage it with the elastic face to form a conical bunt OrtoProfil Guide, 2015). The amputation bunt is so prepared to accept the prosthesis using elastic socks that diminish regressed edema during the first three weeks postoperatively. The difficulty in exercising with the physical therapist increases progressively, strengthening the muscles, lowering contracture and increasing articular mobility.

The occupational therapy will encourage the patient efforts to perform day-to-day activities and gain independence. The availability of the Mobility Assessment Scale makes it possible to provide the prosthetic device and rehabilitation implementation (Orthocare Innovations LLC, 2017).

The prosthetic rehabilitation stage - involves choosing and applying the prosthesis, the patient being 
physically and emotionally prepared to use such a device about one month after surgery. The patient is questioned about his daily activities, the possibility of transfer to the wheelchair, the degree of dependence on medical care. The prothesis will be adapted to the needs and wishes of the patient, the activities performed, age and way of life (Kovac et al, 2015). The physician, the physical therapist and occupational therapist will set up a rehabilitation program that takes into account the patient's particularities and needs.

Integration into the community - the patient gets use of prosthesis and performs family and community activities according to his lifestyle. He will keep in touch with the rehabilitation specialist, as it may be possible for the prosthesis to require some adjustments over time due to the evolution of the amputation bust. The patient will be advised about the changes that need to be made to the home so that he can gain independence in performing his household activities.

The patients' comorbidities, as well as possible the changes in the locomotor system and somatic capacities, will be permanently monitored by regular visits to the physician.

Health education is the responsibility of the medical personnel, instructing the patient to take care of the amputation blunt, the diet to be followed to avoid weight gain and lower risk factors for cardiovascular disease and diabetes, to exercise regularly, to avoid smoking.

\section{Conclusions}

The amputation of a inferior limb has a major impact on the quality of life of the patient. For many patients, it is a loss of self-image and a change in body shape that intertwines with privacy.

The impact on the physical mobility, alteration of skin integrity and comfort, risk of falling, social isolation, mourning, lack of knowledge - are the most important patient care issues.

A satisfactory state of health, adequate healing of the bust, muscle strength, mobility, motivation and family support allow the preparation of a concrete rehabilitation plan.

A complex care provided by the multidisciplinary team - surgeon, nurse, kinesitherapist, prosthetic technician, psychologist, occupational therapist guarantees post-operative physical and emotional recovery, family and social reinsertion.

The monitoring of the vascular affections, including diabetic etiology, as well as morbidities, will be done permanently throughout life.

In Romania it is necessary to draw up a protocol to which all the specialties involved in performing and recovering patients after such interventions will contribute. The establishment of several medical recovery and rehabilitation centers facilitates a return to daily activities and an increase in the quality of life of the patient.

\section{References}

1. Bjerke H, Stuhlmiller D. Extremity vascular trauma. Medscape. October 262015

2. Coletta EM. Care of the elderly patient with lower extremity amputation. J Am Board Fam Pract. 2000;13(1):2334.

3. Dillon MP, Fortington LV, Akram M, Erbas B, KohlerF, Geographic Variation of the Incidence Rate of Lower Limb Amputation in Australia from 2007-12, https://doi.org/10.1371/journal.pone.0170705 [Accessed 14 Nov. 2018]

4. Ertl JP, Pritchett JW, Ertl W, Brackett WJ. Lowerextremity amputations. Medscape. Apr 042016.

5. Esquenazi A, Rehabilitation of amputation and restoration of the prosthesis. From surgery to community reintegration, Disabil Rehabil. 2004 Jul 22-Aug 5; 26 (14-15): 831-6.

6. Esquenazi A, MeierIII RH, Rehabilitation in limb deficiency. 4. Limb amputation, Archives of Physical Medicine and Rehabilitation, 1996 Mar; 77 (3 Suppl): S1828.

7. Guidelines for Patients with inferior limb amputation, OrtoProfil National Rehabilitation Center, Tg.Mures Available at: https://ortoprofil.ro/wpcontent/uploads/2015/12/Ghid-pentru-pacien\%C8\%9Bi -withamputa\%C8\% 9Bii-de-membru-inferior.pdf [Accessed 14 Nov. 2018]

8. Gooday H, J. Hunter, 2004. Preventing falls and stump injuries in lower limb amputees during inpatient rehabilitation: completion of the audit cycle. Clinical Rehabilitation 18:379-390

9. Kovac I, Kauzlaric N, Zivkovic o, Muzic V, Abramovic M. et.all,Rehabilitation of lower limb amputees, Periodicum Biologorum Vol.117, No.I, 147-159, 2015

10. Neil MJE, Pain after amputation, BJA Education, Volume 16, Issue 3, 1 March 2016, Pages 107-112

11. Potter BK, Forsberg JA, Davis TA et al., Heterotopic ossification following combat related trauma, J Bone Joint Surg Am 2010; 92 (Suppl. 2): 74-89

12. Pullen R.L, Jr., Caring for a patient after amputation, Nursing2010, vol.40, p.15

13. Smeltzer SC, Bare BG, Hinkle JL, Cheever KH, eds. Brunner \& Suddarth's Textbook of Medical Surgical Nursing. 11th ed. Philadelphia, PA: Lippincott Williams and Wilkins; 2008.

14. Stepping beyond K-levels Functional Level Assessment System. Centers for Medicare and Medicaid Services (CMS), Gallileo. Orthocare Innovations, LLC. orthocareinnovations.com. $\quad 800.672 .1710$ Available at: https://accessprosthetics.com/wp-

content/uploads/2017/06/Orthocare_FinalWhitepaper10-2710_pdf-1.pdf Accessed 14 Nov. 2018]

15. Swaminathan A, Vemulapalli S, Patel MR, Jones WS. Lower extremity amputation in peripheralartery disease: Improving patient outcomes. Vasc Health Risk Manag. 2014; 10:417-424

16. Tăbîrţă A, Modern approaches in the assessment of disability through amputation of the lower limb, Public Health, Economics and Management in Medicine, No. 5 (69) / 2016 / ISSN 172-8687

17. Vereşiu I.A, Iancu S, Bondor C, Trends in diabetes-related lower extremities in Romania - A five year national evaluation, Diabetes Research \& Clinical Practice, 2015

18. Ziegler-Graham K, MacKenzie EJ, Ephraim PL, Travison $T G$, Brookmeyer R. Estimating theprevalence of limb loss in the United States: 2005 to 2050. Arch Phys Med Rehabil. Mar2008;89(3):422-429.

19. Wartan SW, Hamann W, Wedley JR, McColl I, Phantom pain and sensation among British Veteran Amputees, Br.J Anaesth 1997;78:652-9. 